\title{
Aortic valvotomy for critical aortic stenosis in neonates and infants aged less than one year
}

\author{
SESHADRI BALAJI, BARRY R KEETON, GEORGE R SUTHERLAND, \\ DARRYL F SHORE, JAMES L MONRO \\ From the Wessex Cardiothoracic Centre, Southampton General Hospital, Shirley, Southampton
}

SUMMARY Between April 1974 and December 1987, 20 infants (six under one month of age) (mean weight $4.9 \mathrm{~kg}$ ) underwent surgical valvotomy for critical aortic stenosis. Three of the four patients treated before 1976 died. Since 1979, 16 infants (four neonates) have undergone valvotomy with no deaths. Mortality for the whole group was $15 \%$; in the neonates it was $33 \%$. There were no late deaths. The survivors were followed up for a mean of 3 years 9 months and two required re-operations.

The considerable improvement in surgical results in the past decade should be taken into account when newer techniques such as balloon dilatation are evaluated.

Critical aortic stenosis in infancy has been associated with high mortality and morbidity. ${ }^{1-3}$ Medical treatment alone is unsuccessful. Surgical valvotomy is successful to varying degrees in relieving the stenosis but in infancy it is only palliative and all patients will later require replacement of the aortic valve or root. There has been recent interest in the use of balloon dilatation for this condition. ${ }^{4-6}$ This is why it is important to analyse the results of surgical valvotomy so that the risks to the patient of the various forms of treatment can be established.

This paper reviews our experience with surgical valvotomy in aortic stenosis.

\section{Patients and methods}

Between April 1974 and December 1987, 20 infants including six neonates underwent aortic valvotomy for critical or severe aortic stenosis at Southampton General Hospital. Age at surgery ranged from one day to 51 weeks (mean 14 weeks, median eight weeks). Weight at surgery ranged from 2.5 to $10.9 \mathrm{~kg}$ (mean $4.9 \mathrm{~kg}$ ). Ten patients required emergency surgery and eight of them were moribund before operation with poor perfusion and acidosis and a mean $\mathrm{pH}$ of $7 \cdot 25$. Of the other 12 , three were symptom free while all the rest had signs of heart

Requests for reprints to Mr James L Monro, FRCS, Wessex Cardiothoracic Centre, Level E, East Wing, Southampton General Hospital, Shirley, Southampton SO9 4XY.

Accepted for publication 10 January 1989 failure. Two patients with symptoms had already had an operation: one who had valvotomy at 11 months had had repair of coarctation at the age of two months and repair of ventricular septal defect at three months and the other had undergone repair of coarctation with ligation of the ductus.

The electrocardiogram showed left ventricular hypertrophy in 13 with strain pattern in three. Chest $x$ ray showed a cardiothoracic ratio of $0.47-0.76$ (mean 0.61). Before 1984 all patients underwent cardiac catheterisation, but since then, of ten patients treated, all but three had an operation on echocardiographic grounds alone. Retrospective analysis of the angiogram and/or the echocardiogram showed small left ventricles in three, dilated ventricles in six, and normal sized ventricles in the rest. The left ventricular ejection fraction measured in 15 patients (on the angiogram in five and the echocardiogram in 10) ranged from $10 \%$ to $80 \%$ (mean $45 \%$ ). The pressure gradient across the aortic valve measured in 15 patients (by catheter in seven and Doppler in eight) ranged from $33 \mathrm{~mm} \mathrm{Hg}$ to $120 \mathrm{~mm} \mathrm{Hg}$ (mean $76 \mathrm{~mm} \mathrm{Hg}$ ).

All patients underwent aortic valvotomy under $\underset{Z}{2}$ cardiopulmonary bypass and moderate hypothermia. Cardioplegia was used in all but the first four patients who were treated before 1979. At operation eight patients had tricuspid aortic valves and the rest were bicuspid. Associated lesions corrected at the same operation included ligation of the ductus arteriosus in three, closure of atrial septal defect in two, and repair of coarctation of aorta through a second (left 
Table Data on 20 infants who had valvotomy

\begin{tabular}{|c|c|c|c|c|c|c|c|c|c|c|c|c|c|}
\hline \multirow[b]{2}{*}{ Patient } & \multirow[b]{2}{*}{ Age } & \multirow{2}{*}{$\begin{array}{l}\text { Associated } \\
\text { lesion }\end{array}$} & \multirow{2}{*}{$\begin{array}{l}\text { Cardiac } \\
\text { catheterisation } \\
\text { before } \\
\text { operation }\end{array}$} & \multicolumn{2}{|c|}{$\begin{array}{l}\text { AV gradient } \\
(\mathrm{mm} \mathrm{Hg})\end{array}$} & \multicolumn{2}{|c|}{$L V E F(\%)$} & \multirow{2}{*}{$\begin{array}{l}\text { Pre-op } \\
\text { state }\end{array}$} & \multirow{2}{*}{$\begin{array}{l}\text { Pre-op } \\
p H\end{array}$} & \multirow[b]{2}{*}{ Outcome } & \multirow[b]{2}{*}{$R e-o p$} & \multirow[b]{2}{*}{$A R$} & \multirow[b]{2}{*}{$E F E$} \\
\hline & & & & Before & After & Before & After & & & & & & \\
\hline 1 & $16 \mathrm{wk}$ & & Yes & 37 & - & - & - & $\mathbf{M}$ & $7 \cdot 38$ & Died & & - & + \\
\hline 2 & $33 \mathrm{wk}$ & & Yes & - & 43 & 66 & 70 & $\mathrm{CF}$ & - & Alive & & + & \\
\hline 3 & 3 days & ASD & Yes & 56 & - & - & - & $\vec{M}$ & $7 \cdot 01$ & Died & & - & + \\
\hline 4 & 3 days & ASD & Yes & - & - & 33 & - & 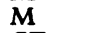 & $7 \cdot 0$ & Died & & - & + \\
\hline 5 & $19 \mathrm{wk}$ & & Yes & 53 & 25 & 14 & 70 & CF & $7 \cdot 41$ & Alive & & ++ & \\
\hline 6 & 7 wk & & Yes & 60 & 40 & - & 89 & $\mathbf{M}$ & $7 \cdot 26$ & Alive & & ++ & \\
\hline 7 & 44 wk & COA, VSD & Yes & 80 & 60 & 76 & 70 & CF & - & Alive & Yes & + & \\
\hline 8 & 37 wk & & Yes & - & 35 & 36 & 50 & CF & $7 \cdot 4$ & Alive & & - & + \\
\hline 9 & 9 wk & & Yes & 33 & 40 & 23 & 82 & $\mathbf{M}$ & $7 \cdot 2$ & Alive & & ++ & \\
\hline 10 & $29 \mathrm{wk}$ & & Yes & 80 & 40 & 71 & 54 & SF & $7 \cdot 21$ & Alive & & - & \\
\hline 11 & $12 \mathrm{wk}$ & & - & - & 30 & 34 & - & $\mathbf{M}$ & $7 \cdot 6$ & Alive & & - & \\
\hline 12 & 5 days & DA & Yes & - & 30 & 40 & 52 & $\mathbf{M}$ & $7 \cdot 3$ & Alive & & + & + \\
\hline 13 & 1 day & DA & - & 100 & 50 & 80 & 73 & $\mathbf{M}$ & $7 \cdot 23$ & Alive & & - & \\
\hline 14 & $6 \mathrm{wk}$ & $\mathbf{C O A}$ & Yes & 100 & 40 & 58 & 60 & CF & $7 \cdot 43$ & Alive & & - & \\
\hline 15 & $11 \mathrm{wk}$ & & - & 40 & 60 & - & 50 & SF & $7 \cdot 42$ & Alive & & - & \\
\hline 16 & 5 wk & COA, DA & Yes & 100 & 35 & 10 & 62 & CF & $7 \cdot 55$ & Alive & Yes & + & + \\
\hline 17 & 5 wk & & - & 120 & $100^{\star}$ & 45 & 89 & CF & $7 \cdot 4$ & Alive & & - & \\
\hline 18 & $51 \mathrm{wk}$ & & - & 100 & 40 & - & 60 & CF & $7 \cdot 52$ & Alive & & + & \\
\hline 19 & 3 wk & & - & 36 & 35 & 53 & 97 & CF & $7 \cdot 58$ & Alive & & - & \\
\hline 20 & 5 days & & - & 40 & 25 & 36 & 67 & SF & $7 \cdot 59$ & Alive & & - & \\
\hline
\end{tabular}

*Dynamic left ventricular obstruction.

AR, aortic regurgitation; ASD, atrial septal defect; AV, aortic valve; CF, cardiac failure; COA, coarctation aorta; DA, ductus arteriosus; EFE, endocardial fibroelastosis; $L V E F$, left ventricular ejection fraction; $M$, moribund; SF, symptom free; VSD, ventricular septal defect; $+=$ mild $++=$ moderate.

thoracotomy) incision in one patient (table). Two had previously undergone coarctation repair, one of whom also had ductus ligation. One of these had a ventricular septal defect closed at a further operation before aortic valvotomy.

\section{Results}

Three of the four patients treated before 1976 died and there have been no deaths since. All the infants who died did so within 24 hours of operation. At the time of operation, two of them (both three days old) were desperately ill; necropsy showed severe widespread endocardial fibroelastosis. The third, a girl aged four months, had had three cardiac arrests at cardiac catheterisation just before operation.

Mortality for the whole group was $15 \%$, and for the neonates it was $33 \%$. Since 1979,16 infants including four neonates have been treated. None has died.

Patients spent 1-13 days (mean three) in intensive care after operation, and ten patients spent longer than 48 hours. Ten patients needed inotropic support for from one hour to six days, and five of them required inotropes for over $\mathbf{4 8}$ hours. Intubation and ventilation was continued for longer than $\mathbf{4 8}$ hours in five patients (maximum five days). Follow up of the 17 survivors ranged from two months to 12 years (mean of 3 years 8 months). Two have required reoperations-one for resection of fibrous subaortic stenosis and one aortic root replacement for severe residual aortic stenosis. Five children still have symptoms and effort intolerance and seven are on medication to counter heart failure. There were no late deaths.
The most recent electrocardiogram showed left ventricular hypertrophy in eight patients with strain pattern in one, and the chest $x$ ray showed cardiothoracic ratios ranging from 0.47 to 0.73 (mean 0.57 ). Doppler estimation of residual aortic stenosis showed gradients ranging from 25 to $100 \mathrm{~mm} \mathrm{Hg}$ (mean $43 \mathrm{~mm} \mathrm{Hg}$ ). The valvar gradient was less than $60 \mathrm{~mm} \mathrm{Hg}$ in all but three: $60 \mathrm{~mm} \mathrm{Hg}$ in two and another had a dynamic subvalve left ventricular outflow tract gradient of $100 \mathrm{~mm} \mathrm{Hg}$ on Doppler which was not present at cardiac catheterisation under general anaesthesia. Eight had aortic regurgitation (mild in five and moderate in three). The left ventricular ejection fraction estimated by echocardiography in 16 survivors ranged from 50 to $97 \%$ (mean 68\%).

None of the patients has had neurological complications caused by their primary cardiac problem or as a result of operation.

\section{Discussion}

Widely varying mortality ranging from $9 \%$ to $66 \%$ has been reported for aortic valvotomy under either conventional cardiopulmonary bypass or inflow occlusion. ${ }^{178}$ The major determinants of mortality are the patient's preoperative clinical state, the size of the left ventricle and aortic annulus, the presence of associated anomalies and, in particular, the presence of mitral stenosis and endocardial fibroelastosis. ${ }^{89}$ The lesion is a variant of the hypoplastic left heart syndrome and in borderline cases categorisation is subjective.

Alternatives to open valvotomy include closed transventricular valvotomy without bypass and 
percutaneous balloon dilatation. Although there is less experience with transventricular valvotomy, the results are comparable to open valvotomy. ${ }^{911}$ Balloon dilatation has produced good results in some patients, ${ }^{45}$ but has damaged the aortic valve and root in others. ${ }^{12}{ }^{13} \mathrm{Wren}$ et al reported a series of thirteen neonates and infants who underwent percutaneous balloon dilatation in which there were five early and two late deaths. ${ }^{6}$ Their children, however, are not strictly comparable with our series. They were smaller and more unwell, two had already undergone surgical valvotomy and two died at subsequent operation.

Clearly, operation is the only alternative when the aortic valve cannot be crossed at catheterisation. Whereas, in theory, open valvotomy might be expected to be more controlled and give better results, proponents of transventricular valvotomy argue that the gelatinous and dysplastic nature of the valve in infants with aortic stenosis makes it unlikely that direct visualisation of the valve would influence the results. ${ }^{9}$ We feel that open valvotomy allows the surgeon to perform a careful commissurotomy in all cases and that direct visualisation helps to decide where and how far the incision ought to run. We believe that our low rates of clinically significant restenosis and regurgitation show that a good balance can be achieved between too large or too small a commissurotomy.

In each series a small proportion of patients needs early re-operation for residual stenosis or regurgitation, and all patients are expected to need replacement of the aortic valve or root in due course. The main advantage of percutaneous balloon dilatation is expected to be the absence of adhesions in the thorax at definitive operation. Also, balloon dilatation can be repeated several times to achieve success. Repeated attempts risk damage to the aortic wall, valve or the femoral artery, however. Also, when balloon dilatation fails the condition of the infant might deteriorate during the procedure. On the other hand, if balloon dilatation is limited to children who are thought to be unsuitable or unfit for operation the risk associated with the procedure would increase, as shown by the results of Wren et al. ${ }^{6}$ Eight of our patients (of whom five survived) were moribund (mean pH 7.25) and might in some centres have been deemed unsuitable for operation. We showed that good results can be achieved even in these very sick infants.

The various methods available for the relief of infant aortic stenosis have their advantages and disadvantages, but which is the best method in children whose condition is stable and who have no adverse features? Newer techniques such as balloon dilatation will need further evaluation before the answer is known and such an assessment must take into account the improved results for valvotomy.

The results of valvotomy have improved significantly in the past decade as shown by our figures and those of Messina et al who reported one operative and no late deaths in 11 neonates.

Until we know more about the results of new techniques, valvotomy will remain the most suitable method for the relief of infant aortic stenosis. The 0 fact that an infant is "too unwell" is no reason to attempt balloon dilatation rather than valvotomy.

\section{References}

1 Keane JF, Bernard WF, Nadas AS. Aortic stenosis surgery in infancy. Circulation 1975;52:1138-43.

2 Kugler JD, Campbell E, Vargo TA, McNamara DG, $\vec{\omega}$ Hallman GL, Cooley DA. Results of aortic valvotomy in infants with aortic valvular stenosis. $J$ Thorac Cardiovasc Surg 1979;78:553-8.

3 Edmunds LH, Wagner HR, Heymann MA. Aortic valvotomy in neonates. Circulation 1980;61:421-7.

4 Lababidi Z, Weinhaus L. Successful balloon valvulo- o plasty for neonatal critical aortic stenosis. Am Heart $J_{0}$ 1986;112:913-6.

5 Rupprath G, Neuhaus KL. Percutaneous balloon $\vec{\nabla}$ valvuloplasty for aortic valve stenosis in infancy. $A m \mathrm{~J}$ 음 Cardiol 1985;55:1655-6.

6 Wren C, Sullivan I, Bull C, Deanfield J. Percutaneous $\vec{\varphi}$ balloon dilatation of aortic valve stenosis in neonates $\mathscr{Q}^{\circ}$ and infants. Br Heart $J$ 1987;58:608-12.

7 Messina LM, Turley K, Stanger P, Hoffman JIE, Ebert PA. Successful aortic valvotomy for severe congenital valvular aortic stenosis in the newborn infant. $J \bar{\partial}$ Thorac Cardiovasc Surg 1984;88:92-6.

8 Pelech AN, Dyck JD, Trusler GA, et al. Critical aortic $\unrhd$ stenosis, survival and management. $J$ Thorac Car- $\overrightarrow{\vec{F}}$ diovasc Surg 1987;94:510-7.

9 Duncan K, Sullivan I, Robinson P, Horvath P, de Leval M, Stark J. Transventricular aortic valvotomy for critical aortic stenosis in infants. $J$ Thorac Cardiovasc Surg 1987;93:546-50.

10 Midgley FM, Perry LW, Shapiro SR, et al. Closed transventricular valvotomy for critical aortic stenosis in the neonate. In: Doyle EF, Engle MA, Gersony WM, Rashkind WJ, Talner NS, eds. Paediatric cardiology. Proceedings of the second world congress. New York: Springer Verlag, 1986:540-1.

11 Trinkle JK, Norton JB, Richardson JD, Grover FL, 음 Noon JA. Closed aortic valvotomy and simultaneous $D$ correction of associated anomalies in infants. $J$ Thorac음. Cardiovasc Surg 1975;69:758-62.

12 Phillips RR, Gerlis LM, Wilson N, Walker DR. Aortic. valve damage caused by operative balloon dilatation $N$ of critical aortic valve stenosis. Br Heart J 1987; N్ 57:168-70.

13 Waller BF, Girod DA, Dillon JC. Transverse aortic wall tears in infants after balloon angioplasty for aortic valve stenosis. J Am Coll Cardiol 1984;4:® 1235-41.

\section{Addendum}

We have operated on a further seven infants aged from five days to four months (mean 6 weeks) including three in the first week of life. One 36 week preterm infant aged six days, weighing $2.4 \mathrm{~kg}$, who also had mitral stenosis and endocar- $§$ dial fibroelastosis died 56 days after the operation, having never left the intensive care unit. The rest survived and arêे well. 